\title{
Integralidade em Projetos Político Pedagógicos para a Formação de Psicólogos
}

\author{
Raphael Klein de Soura* \\ Rosa Maria Rodrigues** \\ Solange de Fátima Reis Conterno***
}

\begin{abstract}
Resumo
Objetivou-se reconhecer nos Projetos Político Pedagógicos - PPP a relação estabelecida entre a formação do psicólogo e o Sistema Único de Saúde, no que se refere ao princípio da integralidade. Estudo exploratório com dados primários levantados em pesquisa documental, que teve como fontes os PPP de cursos de Psicologia do Estado do Paraná sistematizados considerando-se os elementos inerentes aos processos de formação: número de alunos, professores, turmas, carga horária, perfil do egresso, ênfases curriculares, disciplinas voltadas a saúde coletiva e à clínica. Identificou-se que existe a indicação de oferta de disciplinas isoladas, voltadas à saúde coletiva e SUS, especialmente nas ênfases específicas, não refletindo de forma consistente o princípio da integralidade e uma formação voltada para o SUS. Além disso, não estão contempladas nos PPP atividades de formação em campos de promoção, prevenção e recuperação da saúde de forma articulada e carga horária equivalentes.

Palavras-chave: psicologia; formação profissional; projeto político pedagógico; integraliadade.

\section{The Single System of Health and Completeness Political Project for Educational Psychologists}

\begin{abstract}
It has been the aim to recognize in Political Pedagogic Projects, the relation established between the formation of the Psychologist and the Health Single System, regarding the principle of integrality. Exploratory study with primary data collected in documentary research having as sources State of Paraná Psychology coursess PPP systematized considering the elements inherent in the formation processes: number of students, teachers, classes, hours, graduate profile, curricular emphases, courses focused on public health and clinical. The data were analyzed taking as reference the principle of integrality. It was identified that in the surveyed courses there is an indication of isolated disciplines offerings, aimed on public health and Health Single System, especially in specific emphases, not reflecting, consistently, the principle of integrality and focused formation for the Health Single System. Besides that, they don't contemplate educational activities in promoting fields, health prevention and recovery in pivotally and equivalent times.
\end{abstract}

Keywords: psychology undergraduate; political-pedagogical project; vocational training.

* Psicólogo e Mestre em Biociências e Saúde pela Universidade Estadual do Oeste do Paraná.

** Doutora em Educação. Professora Associada do Curso de Graduação em Enfermagem e do PPG em Biociências e Saúde da Universidade Estadual do Oeste do Paraná.

***Doutora em Educação. Professora Adjunta do Curso de Enfermagem da Universidade Estadual do Oeste do Paraná. 


\section{Introdução}

A elaboração e aprovação da segunda Lei de Diretrizes e Bases (LDB n 9394/1996) brasileira desencadeou a reformulação dos documentos legais para a formação escolar, em especial dos currículos dos cursos de graduação que, sob a égide das novas orientações, não seriam mais denominados currículos ou currículos mínimos, mas seriam denominados Diretrizes Curriculares Nacionais (DCN) (Saviani, 1998).

Neste contexto, as instituições e entidades representativas das categorias profissionais foram chamadas a participar e contribuir com a discussão das referidas diretrizes. Os movimentos emergentes do setor produtivo davam suporte às mudanças no campo educacional. Destaque para a reestruturação produtiva destacada, entre outros elementos, por meio do conceito de flexibilidade em relação a organização dos currículos (Catani, Oliveira \& Dourado, 2003), o qual se tornou chave e determinante das mudanças na educação superior desencadeadas após a aprovação da LDB (Brasil, 1996).

Naquele momento, o Ministério da Educação, através de sua Secretaria de Educação Superior emitiu o Parecer MEC/Sisu 776/1997 (Brasil, 1997), que dispunha sobre orientações para as diretrizes curriculares dos cursos de graduação. Estas sinalizavam a importância da colaboração de entidades ligadas à formação e ao exercício profissional, mediadas pela Câmara de Educação Superior do Conselho Nacional de Educação (CNE), no sentido de receber subsídios para a construção das diretrizes curriculares.

Na psicologia, a discussão sobre a formação antecedeu este Parecer, pois em 1995, uma comissão de especialistas fora instituída para organizar o entendimento da categoria sobre o que poderia ser tomado como base para a formação na área considerando-se o momento da profissão, o contexto social e o papel da psicologia no campo da saúde. Entendia-se que, no contexto de ampliação das oportunidades de acesso à educação superior, era preciso sistematizar indicações que visassem à manutenção da qualidade na formação; que os currículos das escolas até então se pautavam em meros instrumentos técnicos focalizados em cargas horárias, disciplinas e conteúdos, os quais deveriam ser construídos em uma perspectiva progressista e emancipadora superando sua concepção restrita (Brasil, 1995).

Do trabalho deste grupo emanaram dez pressupostos que deveriam ser tomados como referência na construção dos projetos pedagógicos dos cursos de psicologia: formação básica, pluralista e sólida; formação generalista; formação interdisciplinar; formação para atuação multiprofissional; formação científica, crítica e reflexiva; efetiva integração teoria e prática; compromisso com as demandas sociais; compromisso ético permeando o currículo; ruptura com o modelo de atuação tecnicista; e definição de terminalidades para a formação (Brasil, 1995).

Construiu-se, pela primeira comissão de especialistas de psicologia, a proposta apresentada em meio às discussões da nova LDB sobre a formação de psicologia. Defendia-se a divisão do currículo entre um núcleo comum, estruturado por seis eixos e um perfil de formação por ênfases profissionais, formato mantido na resolução final das DCN para os cursos de graduação em psicologia (Barbosa, 2007). A proposta da Comissão sintetizava as discussões ocorridas em eventos e pesquisas realizadas por entidades sociais nos anos anteriores.

No ano de 1998 foi constituída uma nova comissão de especialistas, com participação de membros da comissão de 1995, para elaborar as DCN. Momento em que ocorreram diversos debates envolvendo instituições de ensino e entidades profissionais sobre a nova proposta que, no ano de 1999, foi apresentada ao MEC e submetida ao CNE para apreciação, num projeto contendo as DCN para o curso de psicologia. O CNE elaborou e apresentou uma nova proposta, debatida em audiência pública no ano de 2001 (Cirino, Dnupp, Lemos \& Domingues, 2007), a qual recebeu duras críticas das entidades ali presentes, direcionadas especialmente à existência de três perfis para os cursos, licenciatura, bacharelado e de formação de psicólogos. Questionava-se, sobretudo a proposta de ênfases curriculares, que se caracterizavam como aprofundamento dos estudos, em algum domínio da atuação profissional, pois o documento indicava que os cursos deveriam ofertar uma ou mais ênfases, cabendo ao aluno a escolha dentre as opções (Bock, 2002; Cirino, Dnupp, Lemos \& Domingues, 2007).

Apesar das críticas e pedidos de modificação, a proposta foi aprovada pelo CNE, mediante parecer $\mathrm{n}^{\circ} 1314$, de 7 de novembro de 2001. Porém, diante de intensas manifestações de repúdio contra o texto aprovado, avaliado como retrocesso às conquistas realizadas pela categoria, o MEC não homologou a proposta que foi reformulada resultando no parecer $\mathrm{n}^{\circ} 072 \mathrm{CES} / \mathrm{CNE}$, aprovado em fevereiro de 2002, o qual novamente não foi homologado pelo MEC, por não contemplar as considerações da categoria (Bock, 2002).

Uma nova comissão foi constituída no ano de 2003 para debater, principalmente as questões divergentes sobre os diferentes perfis para o curso de psicologia pre- 
sentes nos pareceres 1314/2001 (Brasil, 2001) e 072/2002 (Brasil, 2002). Em dezembro de 2003 foi realizada audiência pública com a proposta de debater as questões relacionadas ao perfil do psicólogo. Após este processo chegou-se a um documento consensual superando-se grande parte das divergências apontadas, culminando no encaminhamento de uma nova proposta, submetida em 19 de fevereiro de 2004 ao CNE e ao MEC. Esta proposta serviu de base para a elaboração do parecer CNE/CES 062/2004 (Brasil, 2004a), homologado em 12 de abril de 2004. Esse documento veio a se constituir na Resolução n 8, de 7 de maio de 2004 (Brasil, 2004b), que instituiu as DCN para o Curso de Graduação em psicologia (Cirino, Dnupp, Lemos \& Domingues, 2007) que, posteriormente foi reeditada por meio da Resolução $\mathrm{n}^{\circ}$. 5, de 15 de março de 2011 (Brasil, 2011).

As ênfases curriculares passaram a compor o documento da área substituindo as tradicionais áreas da psicologia (clínica, escolar e organizacional) e devem ser escolhidas pelos alunos nos últimos períodos do curso podendo interligar, inclusive aspectos de duas ou mais áreas (Brasileiro \& Souza, 2010).

As DCN para os cursos de graduação em psicologia orientam os princípios, fundamentos, condições de oferta para as IES organizarem seus cursos de graduação, permitindo flexibilidade na construção dos currículos; apresentam possibilidades de diferentes arranjos voltados para a realidade local e social. Apesar do intenso debate já mencionado em torno da estruturação das DCN, ainda prevaleceram pontos polêmicos, tais como as "especializações prematuras" (Brasileiro \& Souza, 2010).

Há um consenso nas discussões envolvendo os cursos de graduações da área da saúde, especialmente em seus pareceres precedentes à emissão das diretrizes curriculares específicas de cada curso, de que é preciso voltar a formação para as necessidades do Sistema Único de Saúde (SUS), portanto, este consenso colocou-se como imagem objetivo para a área.

No entanto, apesar dos avanços na compreensão da atuação do psicólogo, comparados ao Currículo Mínimo de 1962 e do aumento significativo de psicólogos que atuam no SUS ao longo das décadas, a formação do psicólogo continua sendo ofertada em moldes próximos do modelo clínico tradicional, centrado no atendimento psicoterapêutico individual (Ribeiro \& Luzio, 2008; Hüning, Silva, Silva \& Lessa, 2013; Ferreira Neto, 2010).

O exame do conteúdo das DNC não explicita claramente uma aproximação da formação em psicologia voltada para o SUS. No entanto, o Conselho Federal de Psicologia (CFP) indica que as DCN abrem margens para os cursos ofertarem ênfases curriculares em questões relativas às políticas públicas e complementa que não é possível a formação em psicologia estar afastada das práticas profissionais da rede pública de saúde (Brasil, 2006).

Todavia, em relação às reformas curriculares é fundamental a construção de uma proposta político-pedagógica que dialogue com as políticas públicas, que não reduza essa relação a poucas disciplinas. A mera inclusão, nas grades curriculares dos cursos, de disciplinas de políticas de saúde não garante mudanças efetivas na formação (Brasil, 2006).

O conceito de saúde a ser superado é definido como a ausência de doenças configurando-se numa concepção restritiva, alicerçada no modelo que privilegia práticas prioritariamente curativas. Trata-se de uma definição que nega alternativas ao tema da saúde e reduz o conceito de saúde, ao lançar maior ênfase ao tratamento e à prevenção das doenças e lesões, como sendo os únicos determinantes da saúde. A definição de saúde é um conceito que pode depender de variados fatores, expectativas e posturas diante da vida, contexto histórico e/ou visão de mundo (Czeresnia \& Freitas, 2003).

Do conceito ampliado de saúde decorre a noção de direito à saúde materializado na garantia pelo Estado da criação das condições para que as pessoas tenham uma vida digna e que alcancem o "acesso universal e igualitário às ações e serviços de promoção, proteção e recuperação de saúde, em todos os níveis, a todos os habitantes do território nacional, levando ao desenvolvimento pleno do ser humano em sua individualidade" (Brasil, 1986, p. 4).

Quando se relaciona este conceito ampliado de saúde como categoria analítica para os processos formativos implica considerar que a formação profissional em saúde, seja através de seus pressupostos pedagógicos, seja pelas estruturas curriculares deve garantir que a formação, da mesma forma seja pensada numa concepção ampliada para o que, o princípio da integralidade emerge como elemento estruturante da formação em saúde, assim como da organização da assistência em saúde.

A integralidade conforme a Lei Federal $n^{\circ}$. 8.080/1990 é entendida como: “(...) integralidade de assistência, (...) conjunto articulado e contínuo das ações e serviços preventivos e curativos, individuais e coletivos, exigidos para cada caso em todos os níveis de complexidade do sistema" (Brasil, 1990, p. 3). Ou como definem Noronha, Lima e Machado (2008, p. 439): 
[...] um conjunto articulado e contínuo de ações e serviços preventivos e curativos, individuais e coletivos, exigidos para cada caso em todos os níveis de complexidade do sistema. A ideia é que as ações voltadas para a promoção da saúde e a prevenção de agravos e doenças não sejam dissociadas da assistência ambulatorial e hospitalar voltadas para o diagnóstico, o tratamento e a reabilitação [...].

$\mathrm{Na}$ especificidade da psicologia a integralidade poderia ser expressa pela

[...] recusa à fragmentação do saber psicológico, recusa ao reducionismo psicologicista, individualizante e objetificador, ampliação das possibilidades de modos de atuação que não somente as centradas no profissional liberal, abertura e sensibilidade às competências e relações dialógicas. Dessa forma, acreditamos que os sentidos de formação generalista possam ser minimamente articulados aos princípios do SUS e, em especial, ao de integralidade (Brasil, 2006, p. 38).

Sustentar a formação em saúde no princípio da integralidade significa considerar que a formação deve prever a integralidade das ações de saúde e a integralidade do sujeito assistido pelos profissionais de saúde, através de ações de promoção, prevenção e recuperação da saúde. Da mesma forma, a formação na graduação em psicologia, pautada na integralidade, deverá contemplar ações de formação em campos de promoção, prevenção e recuperação da saúde.

Pressupõe-se que, apesar das discussões sobre a formação na área da saúde e na psicologia indicarem a formação para atuação no SUS, os cursos de psicologia mantêm seus projetos de formação alicerçados na assistência psicológica individual e no modelo de profissão liberal o que pode distanciar a formação para a integralidade prevista neste sistema de saúde. Tem-se como objetivo reconhecer em Projetos Político Pedagógicos, a relação estabelecida entre a formação do psicólogo e o SUS, no que se refere ao princípio da integralidade.

\section{Material e método}

Trata-se de um estudo exploratório, através de pesquisa documental, tendo como fontes, dados primários coletados de Projetos Político Pedagógicos (PPP) de cursos de psicologia do Estado do Paraná implantados no período de 1962 a 1992; em situação regular perante o Ministério da Educação.

Encontrou-se em funcionamento, em 2016, 38 cursos, dentre os quais, seis foram selecionados, conforme os cri- térios de inclusão e exclusão. Foram critérios de inclusão: cursos de graduação em psicologia, com sede no Estado do Paraná; implantados no período de 1962 a 1992 e em situação regular. E, de exclusão: cursos implantados a partir do ano de 1993 e/ou cursos em situação não regular. Tomou-se como limite temporal, o ano de 1962 por ser o início da formação de nível superior em psicologia no Paraná e 1992 por ser o início da implantação do SUS.

De acordo com os critérios, no estado do Paraná, são ofertados, em situação regular, em seis Instituições de Ensino Superior, os cursos de psicologia com abertura no período de 1962 a 1992 dos quais três de natureza jurídica pública e três de natureza jurídica privada (Brasil, 2014). Destes, três aceitaram participar da pesquisa (dois públicos e um privado). Os dados foram acessados nos arquivos das coordenações dos cursos de psicologia das instituições selecionadas, após a autorização e disponibilização dos documentos pelas coordenações, a partir da assinatura do termo de autorização do campo para realização do estudo.

A coleta de dados realizou-se por meio de formulário próprio adaptado do modelo utilizado por Rodrigues e Caldeira (2009) contemplando: quantitativo de cursos; ênfases ofertadas; números de professores que ministram aulas no curso; oferta de turmas e número de turmas; número de alunos por turma; perfil profissional pretendido do egresso; carga horária do curso; carga horária prática; carga horária mista (teoria/prática); carga horária na área clínica e ementas que contemplam conteúdos direcionados à formação para o SUS.

Os dados foram organizados e analisados de forma descritiva, referenciados aos estudos da área que abordam a temática. As instituições estão identificadas por números: IES1, IES2 e IES3. A pesquisa foi aprovada pelo Comitê de Ética em Pesquisa com seres humanos, conforme Parecer no ${ }^{\circ}$ 1.134.635, de 1 de julho de 2015.

\section{Resultados}

Os Projetos Político Pedagógicos foram sistematizados considerando-se os elementos inerentes aos processos de formação, conforme instrumento de coleta de dados. O quadro 1 mostra os dados de caracterização dos três cursos estudados expondo a forma de oferta, número de turmas por ano, número de alunos por turma, números de professores que ministram aulas no curso, carga horária total do curso, carga horária de atividades complementares, carga horária da matriz comum, carga horária na ênfase escolhida, carga horária em atividades na área da saúde coletiva, carga horária na área da clínica e as ênfases ofertadas. 
Quadro 1: Projetos Político Pedagógicos dos cursos de Psicologia das IES 1, IES 2 e IES 3.

\begin{tabular}{|c|c|c|c|}
\hline VARIÁVEIS & IES 1 & IES 2 & IES 3 \\
\hline Oferta & Anual & Anual & Semestral \\
\hline Número de turma por ano & 2 & 2 & $\begin{array}{l}2 \text { turmas no } 1^{\circ} \text { Semestre; } \\
2 \text { turmas no } 2^{\circ} \text { Semestre. }\end{array}$ \\
\hline Número de alunos por turma & 40 & 40 & 50 \\
\hline $\begin{array}{l}\text { Números de professores que } \\
\text { ministram aulas no curso }\end{array}$ & 78 & 89 & 53 \\
\hline $\begin{array}{l}\text { Perfil do egresso } \\
\text { (síntese feita pelos autores) }\end{array}$ & Sólida formação científica & Formar para pesquisa & $\begin{array}{l}\text { Atuar nas diversas áreas da } \\
\text { psicologia }\end{array}$ \\
\hline Carga horária Total do curso & 5119 horas & 4564 horas & 4002 horas \\
\hline $\begin{array}{l}\text { Carga horária atividades com- } \\
\text { plementares }\end{array}$ & 240 horas & 180 horas & 240 horas \\
\hline Carga horária matriz comum & 3655 horas & 2104 horas & 3618 horas \\
\hline $\begin{array}{l}\text { Carga horária na Ênfase esco- } \\
\text { lhida }\end{array}$ & 1224 horas & 1140 horas & 144 horas \\
\hline Número de ênfases ofertadas & 3 & 3 & 2 \\
\hline Enfases ofertadas & $\begin{array}{l}\text { - Ênfase I - Saúde e Pro- } \\
\text { cessos Clínicos; } \\
\text { - Ênfase II - Educação; } \\
\text { - Ênfase III - Trabalho. }\end{array}$ & $\begin{array}{l}\text { - Ênfase I - Psicologia e } \\
\text { Processos de Prevenção } \\
\text { e Promoção da Saúde; } \\
\text { - Ênfase II - Psicologia e } \\
\text { Processos Clínicos; } \\
\text { - Ênfase III - Psicologia e } \\
\text { Processos Institucionais e } \\
\text { Educativos. } \\
\end{array}$ & $\begin{array}{l}\text { - Ênfase I - Promoção e } \\
\text { prevenção da saúde; } \\
\text { - Ênfase II - Processos } \\
\text { investigativos institucio- } \\
\text { nais e clínicos. }\end{array}$ \\
\hline $\begin{array}{l}\text { Carga horária em atividades na } \\
\text { área da saúde coletiva }\end{array}$ & $\begin{array}{l}\text { - Matriz comum: } 68 \text { horas; } \\
\text { - Enfase I: } 68 \text { horas. }\end{array}$ & $\begin{array}{l}\text { - Matriz Comum: } 60 \text { horas; } \\
\text { - Ênfase I: } 540 \text { horas; } \\
\text { - Ênfase II: } 180 \text { horas; } \\
\text { - Ênfase III: } 120 \text { horas. }\end{array}$ & $\begin{array}{l}\text { - Matriz Comum: } 216 \text { ho- } \\
\text { ras; } \\
\text { - Ênfase I: } 144 \text { horas. }\end{array}$ \\
\hline Carga horária na área da clínica & $\begin{array}{l}\text { - Matriz comum: } 60 \text { horas. } \\
\text { - Ênfase I: } 540 \text { horas; } \\
\text { - Ênfase II: } 180 \text { horas; } \\
\text { - Ênfase III: } 120 \text { horas. }\end{array}$ & $\begin{array}{l}\text { - Matriz Comum: } 60 \text { horas. } \\
\text { - Ênfase II: } 540 \text { horas. }\end{array}$ & $\begin{array}{l}\text { - Matriz Comum: } 180 \text { ho- } \\
\text { ras. }\end{array}$ \\
\hline
\end{tabular}

Fonte: Projetos Político Pedagógicos

Além dos dados acima, buscou-se identificar nos PPP elementos que fizessem referência à formação para além dos ambientes tradicionais, alinhados à assistência individual e exclusiva às questões psicológicas, especialmente as ementas dos cursos e suas respectivas cargas horárias voltadas para atuação no SUS.

Dentre as ementas da IES 1, que se alinham a formação para o SUS destacam-se a Disciplina: Práticas em Saúde mental e Processos Clínicos (68 horas), ofertada na Ênfase em Saúde e Processos Clínicos, com a seguinte descrição:

Diagnósticos e intervenções clínicas em saúde mental em instituições. Fornecer ao aluno subsídios teórico-metodo- lógicos para a realização das Práticas em Saúde Mental e Processos Clínicos; [...] conhecimento da política de saúde mental e suas implicações sócio-político-econômicas.

$\mathrm{Na}$ IES 2 identificou-se na matriz comum as disciplinas: Introdução aos Processos de Promoção e Prevenção em Saúde (72 horas); na Ênfase Psicologia e Processos de Prevenção e Promoção da Saúde as disciplinas: Psicologia e Políticas Públicas (72 horas); Psicologia e Tratamento em saúde (72 horas); Promoção de Saúde e Qualidade de Vida (72 horas); Contribuições da Psicologia para o Trabalho em Saúde (72 horas); Psicologia Social e Questões contemporâneas (30 horas); Saúde Coletiva (30 horas). $\mathrm{Na}$ Enfase Psicologia e Processos Institucionais e Edu- 
cativos, a disciplina: Psicanálise, Trabalho e Instituições Públicas (30 horas).

Dentre as ementas da IES 2 destaca-se nas ementas da matriz comum a da disciplina: Introdução aos Processos de Promoção em Saúde (72 horas) que prevê:

Fundamentos e conceitos no campo da saúde. A constituição, representações e conceituações histórico-culturais da saúde e da doença como campo de saberes e práticas de caráter transdisciplinar em indivíduos e populações. Modelos de atenção e organização dos serviços de saúde. Introdução à questão da promoção, prevenção e tratamento em diferentes contextos no campo da Saúde.

Na ênfase em Psicologia e Processos de Prevenção e Promoção da Saúde na qual consta a Disciplina: Psicologia e Políticas Públicas (72 horas) cuja ementa aborda:

Aspectos históricos e contemporâneos da área de Políticas Públicas. Processos de formulação, administração e avaliação das Políticas Públicas. As políticas públicas relacionadas à atuação do psicólogo na área da saúde e na área social. A construção do Sistema Único de Saúde como projeto político. Os conceitos de redes, coletivos e gestão nas políticas de saúde. Diretrizes de atuação do psicólogo na saúde. As políticas de proteção social dirigida aos diversos grupos. Avaliação e implantação de medidas de proteção social. Os conceitos de risco, vulnerabilidade e proteção social. Diretrizes de atuação do psicólogo na área social em sua intersecção com a saúde.

Na IES 3 encontra-se, na matriz comum as disciplinas: Determinantes sociais da Saúde e desigualdades sociais no Brasil (30 horas); Psicologia da saúde (30 horas); Psicologia comunitária e da saúde (30 horas); Psicologia e políticas públicas (36 horas); Saúde coletiva (36 horas). Ênfase Promoção e prevenção da saúde: Psicologia comunitária e da saúde (72 horas).

Dentre outras ementas da IES 3, destaca-se a Disciplina da Matriz comum: Psicologia da saúde (36 horas):

História da psicologia da saúde. Níveis de atenção em saúde. Especificidades da prática psicológica em hospital. Necessidades psicológicas do indivíduo e da família frente à hospitalização. Atuação do psicólogo junto a diferentes especialidades médicas e equipes de saúde.

No Estado do Paraná, em consulta a dados disponíveis nas páginas dos cursos identificados na base de dados do e-Mec existem 38 cursos em funcionamento, dos quais 11 indicam em suas propostas curriculares a formação generalista, ao não indicarem as ênfases previstas nas DCN, e 27 indicam a oferta de 2 ou mais ênfases.

\section{Discussão}

Destaca-se nos cursos pesquisados a diferença entre o quantitativo de professores dos três cursos, uma vez que a IES 3, que oferta quatro turmas no ano, com cinquenta alunos cada (duzentas vagas anuais), tem o menor número de professores $(n=53)$, em comparação aos dois cursos que ofertam respectivamente duas turmas no ano com quarenta alunos cada (80 vagas anuais) e contam com um número maior de professores (IES 1, $\mathrm{n}=78$; IES $2, \mathrm{n}=89)$.

O perfil do egresso nos três cursos apresenta-se substancialmente diferenciado. Constata-se que o perfil do egresso da IES 1 busca contemplar diferentes aspectos da atribuição do psicólogo aproximando-se em alguma medida dos princípios e compromissos expressos nas DCN do curso de psicologia que indicam, em seu artigo $3^{\circ}$, que a formação do psicólogo deve se voltar para a atuação profissional, para a pesquisa e para o ensino (Brasil, 2011).

O perfil do psicólogo da IES 2, está integralmente voltado para a pesquisa sugerindo que esta IES forma psicólogos pesquisadores, uma das dimensões indicadas nas DCN. Entretanto, ao se observar os objetivos do curso, esta dimensão é ampliada e passa a considerar a atuação do psicólogo em outras áreas como na assistência e nas organizações.

Já o perfil do psicólogo da IES 3, propõe e detalha as áreas de atuação de psicologia seguindo, em grande medida, os princípios e compromissos das DCN, indicação que é mantida no objetivo do curso.

Estudo sobre a atuação dos psicólogos no Brasil realizado em 2008 revelou que havia diversificação de campos e locais de trabalho, mas nos quais o psicólogo desenvolvia atividades semelhantes, tais como a avaliação psicológica, psicodiagnóstico e aplicação de testes. Concluem que, embora não se sintam mudanças tão significativas no fazer cotidiano destes profissionais observa-se que eles estão atuando para além da clínica e substituindo o modelo de atendimento clínico, pelos de intervenção grupal com importante ênfase no social (Bastos, Gondim \& Borges-Andrade, 2010).

A carga horária total dos cursos mostra diferenças significativas, sendo que o curso com maior carga horária (IES 1 = 5119 horas), em relação com o de menor carga 
horária (IES $3=4002$ horas) tem uma diferença de 1117 horas. Disparidade que se mantém ao se comparar a diferença entre a carga horária das ênfases no curso com maior carga horária (IES $1=1224$ horas), em relação a menor (IES $3=144$ horas), constatando-se uma diferença entre eles de 1080 horas.

A definição legal para o limite mínimo de carga horária dos cursos de psicologia está estabelecida na Resolução MEC/CNE/CES no 2/2007, como 4000 horas (Brasil, 2007). Portanto, do ponto de vista legal, nenhum dos cursos está desatento ao ordenamento legal no que se refere à carga horária.

Defende-se que a formação nos cursos da área da saúde articule, de forma equilibrada, seus tempos de formação teórica e prática, o que equivale a dizer, que teoria e prática devem ter cargas horárias disponíveis em proporções aproximadas. Ao analisar esta dimensão do PPP dos cursos, observa-se nas IES 1 e IES 3, proporções equilibradas, já para a IES 2 a carga horária teórica da matriz comum é significativamente maior que sua carga horária prática. Destaca-se por outro lado, que na IES 3, não há carga horária prática destinada ao cumprimento das ênfases que o curso prevê, dado relevante, uma vez que a ênfase seria a maior vivência profissional numa determinada realidade de trabalho, o que não está previsto nesta proposta de formação.

A análise das ênfases ofertadas pelos três cursos demonstra que a ênfase em processo de prevenção e promoção de saúde se repete em dois cursos e a ênfase em processos clínicos, com algumas variações se repete nos três cursos. Esta configuração pode revelar a tentativa dos cursos de possibilitar a escolha por uma ênfase que considere outros aspectos, além das questões clínicas, o que pode indicar que os cursos têm buscado formar, em alguma medida para o SUS. Por outro lado, é preciso registrar que os três cursos têm como opção a ênfase em processos clínicos, mostrando a força que esta dimensão possui nos PPP da psicologia.

As DCN indicam que os currículos devem articular conhecimentos, habilidades e competências em torno de seis eixos estruturantes, que deveriam orientar a construção de todas as disciplinas do currículo do curso: fundamentos epistemológicos e históricos; fundamentos teórico-metodológicos; procedimentos para a investigação científica e a prática profissional; fenômenos e processos psicológicos; interfaces com campos afins do conhecimento; e práticas profissionais voltadas para assegurar um núcleo básico de competências (Brasil, 2004b).
As ênfases curriculares são apresentadas e definidas no artigo 10 das DCN, indicando que devido:

[...] a diversidade de orientações teórico-metodológicas, práticas e contextos de inserção profissional, a formação em psicologia diferencia-se em ênfases curriculares, entendidas como um conjunto delimitado e articulado de competências e habilidades que configuram oportunidades de concentração de estudos e estágios em algum domínio da psicologia (Brasil, 2004b, p. 4).

Da mesma forma, o Parecer do Conselho Nacional de Educação n ${ }^{\circ}$ 062/2004 (Brasil, 2004a, p. 3), define ênfases curriculares como "um conjunto delimitado e articulado de competências e habilidades que configuram oportunidades de concentração de estudos e estágios em algum domínio da psicologia”. Elas devem ser suficientemente abrangentes para não configurarem especializações, porém assegurar o respeito às singularidades institucionais, às vocações específicas e aos contextos regionais (Brasil, 2004a).

Na sua organização, os cursos deverão descrever e detalhar em sua concepção e estrutura, as ênfases curriculares que adotarão, conforme detalhados nos artigos 11 e 12:

[...] a definição das ênfases curriculares, no projeto do curso, envolverá um subconjunto de competências e habilidades dentre aquelas que integram o domínio das competências gerais do psicólogo, compatível com demandas sociais atuais e ou potenciais, e com a vocação e condições da instituição.

$\int 2^{\circ}$ A partir das competências e habilidades definidas, o projeto de curso deverá especificar conteúdos e experiências de ensino capazes de garantir a concentração no domínio abarcado pelas ênfases propostas. $\int 3^{\circ} \mathrm{A}$ instituição deverá oferecer, pelo menos, duas ênfases curriculares que assegurem possibilidade de escolha por parte do aluno. $\ 4^{\circ} \mathrm{O}$ projeto de curso deve prever mecanismos que permitam ao aluno escolher uma ou mais dentre as ênfases propostas (Brasil, 2004b, p. 5).

A divisão núcleo comum e ênfase, proposta na DCN, é indicada para permitir maior flexibilização e variabilidade nos cursos. As diretrizes consideram que as ênfases não devem ser específicas demais para não se caracterizarem como especializações precoces, muito menos a separação da teoria e da prática (Bastos, 2002). 
Já o entendimento do Conselho Federal de Psicologia (CFP), em Brasil (2006) indicava que, ao prever uma abertura para as inovações em psicologia, a definição de ênfases, poderia tender a manutenção do que já existe, pois, a formação no Brasil é identificada dentre outras, pela hegemonia da psicologia aplicada, que é caracterizada pela perspectiva tecnicista. A psicologia aplicada é responsável, em grande parte, pela histórica fragmentação da formação consolidada tradicionalmente na Psicologia Clínica, Psicologia Escolar e Psicologia Organizacional.

Para a construção de ênfases amplas, sugerimos a construção de ênfases substantivas, por exemplo: saúde. Não se trata da psicologia da saúde, mas saúde enquanto substantivo. O processo de substantivar as ênfases se dá por meio de questões centrais na vida em sociedade; no caso do exemplo saúde, é estabelecer articulações com os processos de saúde e adoecimento das pessoas, os processos de ensino-aprendizagem, as novas tecnologias, as redes de atenção, as comunidades, o consumo, a diversidade organizacional, a gestão do trabalho, o trabalho formal e o informal, o trabalho infantil (Brasil, 2006, p. 29).

Deste modo, a concepção de ênfases amplas, substantivas e, portanto, temáticas pode ser um meio viável, um caminho para romper com a lógica da psicologia aplicada e com as chamadas habilitações, pois é comum perceber que os cursos estão seguindo no encadeamento do perfil formativo do psicólogo ao repetir as áreas tradicionais, por meio das ênfases. As políticas públicas oferecem um vasto campo de temas que podem ser explorados nessa perspectiva. Os princípios do SUS oferecem um arcabouço de oportunidades para as rupturas almejadas (Brasil, 2006). Entretanto parece persistir a atuação e formação nas áreas clássicas de avaliação, psicodiagnóstico e a clínica em geral, (...) podendo revelar "o viés clínico presente em grande parte do nosso sistema de ensino em psicologia" (Bastos, Gondim \& Borges-Andrade, 2010, p. 268).

Pressupõe-se que uma formação que pretende contemplar o SUS, além dos aspectos clínicos precisa disponibilizar tempos e espaços para vivência do SUS, o que pode acontecer nos ambientes em que acontecem ações de saúde coletiva. Sob este aspecto observa-se semelhanças de carga horária entre os cursos das IES 1 e IES 2 e diferença entre estes com a IES 3, a qual destina mais de três vezes a carga horária para formação na saúde coletiva. Ou seja, a IES 1 com 68 horas, a IES 2 com 60 horas e a IES 3 com 216 horas específicas para a saúde coletiva. Dados que são comprovados pela análise das ementas das disciplinas, da IES3, que se voltam especificamente para o SUS.

Estas mesmas diferenças encontram-se ao sistematizar a carga horária na área clínica na matriz comum, quando se observa que a IES 1 oferta 60 horas, a IES 2 ofertas 60 horas, e a IES 3 ofertas 180 horas, destinadas especificamente para a área clínica.

As instituições de ensino, como formadoras são o centro da educação sistemática, amparados pelas DCN, possuem como função básica a transmissão organizada do conhecimento. É por meio do conteúdo e das experiências de aprendizagem que elas transmitem, de forma sistematizada, o conhecimento e os valores tidos como desejáveis na formação das gerações subsequentes (Haydt, 2006).

O Projeto Político Pedagógico é de fundamental importância neste processo, visto que, o PPP "tem sido objeto de estudos para professores, pesquisadores e instituições educacionais em nível nacional, estadual e municipal, em busca da melhoria da qualidade do ensino". O projeto remete a um rumo, uma direção com sentido explícito bem como um compromisso definido coletivamente, por isso ele também é um projeto político, devido ao fato da articulação com o compromisso sociopolítico com o contexto em que se insere. Ele é pedagógico, pois define as ações educativas e as características necessárias às instituições para cumprirem seus propósitos (Veiga, 2007 p. 11).

O estudo do movimento interno das mudanças na formação em psicologia no Brasil revela o embate entre projetos de formação; entendimentos do que seja a atuação profissional, do papel que a categoria deve assumir enquanto sujeitos produtores de saúde; o movimento em torno da configuração de uma prática profissional que ouse se universalizar acompanhando os preceitos do SUS. Neste embate é possível perceber que há movimentos de avanços e retrocessos que parecem tencionados pelos valores consolidados, pelo referencial de prática liberal e de atenção individual, nem sempre atenta ao contexto da saúde da coletividade.

É possível afirmar que a discussão acerca da formação captou as indicações gerais que foram produto do movimento de criação do SUS e que tencionavam os processos de formação de profissionais de saúde a voltar o olhar para a formação de sujeitos comprometidos com a coletividade, com a integralidade. Esta afirmação se pode averiguar nas formulações emanadas da categoria no ano de 1995, quando delimitava suas diretrizes de 
formação, aqui tomadas como pressupostos da psicologia para a formação desejada na área.

Naquele documento indicava-se a premência de uma formação pluralista e sólida; da formação generalista, interdisciplinar; da atuação multidisciplinar; formação crítica e reflexiva; articulação/integração teoria e prática; compromisso com as demandas sociais; compromisso ético; ruptura com a atuação tecnicista e com as terminalidades (Brasil, 1995).

Pressupostos que estavam na base da discussão de outros cursos da área (Rodrigues, 2005), e que foram tencionados quando da emissão dos documentos definitivos que, no limite mantiveram a formação tendo como norte as ênfases curriculares. Embora o entendimento de ênfases pareça um avanço, em comparação com as especialidades que configuravam os currículos, expressas na formação do professor, do psicólogo e do bacharel elas mantêm um tom de habilitação, já na graduação, o que desafina com os pressupostos acima expostos e que foram o consenso da área quando, coletivamente discutiu sua formação.

\section{Considerações Finais}

Analisando os documentos norteadores da formação do psicólogo, explorados nesta pesquisa, não se observa que a área da psicologia tenha indicado uma clara ligação da formação com o SUS. Mas é possível afirmar, que formar para o SUS perpassou de forma implícita os documentos da área.

Nota-se que nos Projetos Político Pedagógicos dos cursos analisados, existe a intenção da formação do psicólogo voltada para o Sistema Único de Saúde, porém a formação voltada para os Processos Clínicos tradicionais não deixa de figurar entre as importantes ênfases que os alunos podem escolher.

Ao analisar os Projetos Político Pedagógicos, observa-se que existe a indicação de oferta de disciplinas voltadas a área da saúde e o SUS. Porém, não são disciplinas da matriz comum e sim ofertadas nas ênfases. Sendo assim, pode existir uma fragmentação na formação, não atendendo ao princípio da Integralidade.

A integralidade das ações de saúde e a integralidade do sujeito assistido pelos profissionais de saúde nos Projetos Pedagógicos de cursos analisados foi pouco evidenciada, pois não são ofertadas na matriz comum dos cursos, disciplinas que abordem ações de promoção, prevenção e recuperação da saúde. Indicando neste caso, que a formação do psicólogo pode não estar em consonância com o Princípio da Integralidade.
As discussões sobre a formação na área da saúde e na psicologia indicarem a formação para atuação o Sistema Único de Saúde, mas permanece a área organizada na perspectiva de ênfases o que pode distanciar a formação para a integralidade prevista no SUS. Restaria saber o quanto cada ênfase é escolhida pelos alunos para dimensionar se, de fato, as alternativas de alargamento da formação estão conseguindo alcançar suas pretensões formativas.

O estudo tem como limite, o número de PPP analisados e poderia ser estendido a mais cursos ampliando o raio de análises e possíveis distanciamentos ou similaridades entre os dados identificados.

\section{Referências Bibliográficas}

Barbosa, M. D. L. (2007). Estudo sobre a reestruturação curricular do curso de Psicologia da Universidade de Brasília: o processo e seus produtos. Dissertação de mestrado, Instituto de Psicologia, Universidade de Brasília, Distrito Federal.

Bastos, A. V. B. (2002). Perfis de formação e ênfases curriculares: o que são e por que surgiram? Revista do Departamento de Psicologia, UFF, 14(1), 31-57.

Bastos, A. V. B; Gondim, S. M. G.; Borges-Andrade, J. E. (2010). O psicólogo brasileiro: sua atuação e formação profissional. O que mudou nestas últimas Décadas? In: Yamamoto, A. L.; Costa, A. L. F. (Orgs.). (2010). Natal, RN: EDUFRN.

Bock, A. M. B. (2002). Diretrizes Curriculares: que direção queremos para a formação? Revista do Departamento de Psicologia - UFF, 14, 31-57, Rio de Janeiro.

Brasil. (1986). Conselho Nacional de Saúde. $8^{a}$ Conferência Nacional de Saúde. Relatório final. Brasília-DF.

Brasil. (1990). Lei Federal no 8.080, de 19 de setembro de 1990. Dispõe sobre as condições para a promoção, proteção e recuperação da saúde, a organiz̧ação e o funcionamento dos serviços correspondentes e dá outras providências. Brasília, DF.

Brasil. (1995). Ministério da Educação. Comissão de Especialistas de Ensino de Psicologia. A Formação em Psicologia contribuições para reestruturação curricular e avaliação dos cursos.

Brasil. (1996). Presidência da República. Lei Federal n 9493, de 20 de dezembro de 1996. Estabelece as Diretrizes e Bases da Educação Nacional. Brasília, DF

Brasil. (1997). Conselho Nacional de Educação/Câmara de Educação Superior. Parecer $\mathrm{n}^{\circ}$. 776/1997, de 03 de dezembro de 1997. Orienta para as diretrizes curriculares dos cursos de graduação. Brasília-DF.

Brasil. (2001). Conselho Nacional de Educação / Câmara de Educação Superior. Parecer $n^{\circ}$. 1.314/2001, de 07 de novembro de 2001. Diretrizes Curriculares para o Curso de Graduação em Psicologia.

Brasil. (2002). Conselho Nacional de Educação / Câmara de Educação Superior. Parecer $\mathrm{n}^{\circ}$. 072/2002, de 20 de fevereiro de 2002. Retificação do Parecer CNE/CES de 1.314/2001 relativo às Diretrizes Curriculares Nacionais para os cursos de graduação em Psicologia. Brasília-DF.

Brasil. (2004a). Conselho Nacional de Educação. Parecer n ${ }^{\circ} .062 / 2004$, de 19 de fevereiro de 2004. Proposta de Diretrizes Curriculares para o Curso de Graduação em Psicologia.

Brasil. (2004b). Ministério da Saúde e da Educação. Resolução n ${ }^{\circ}$. 8, de 7 de maio de 2004. Institui as Diretrizes Curriculares Nacionais para os Cursos de Graduação em Psicologia.

Brasil. (2006). CFP - Conselho Federal de Psicologia. I Fórum Nacional de Psicologia e Saúde Pública - Relatório Final. Brasília, DF.

Brasil. (2007). Conselho Nacional de Educação / Câmara de Educação Superior. Resolução no. 2/2007, de 18 de junho de 2007. Dispõe sobre carga horária mínima e procedimentos relativos à integralização e duração dos cursos de graduação, bacharelados, na modalidade presencial.

Brasil. (2011). Ministério da Saúde e da Educação. Resolução nº 5 , de 15 de março de 2011. Diretrizes Curriculares Nacionais para os Cursos de Graduação em Psicologia. 
Brasil (2014). Ministério da Educação. Instituto Nacional de Estudos e Pesquisas Educacionais Anísio Teixeira - INEP. Sistema e-Mec. Cadastro de Instituições de Ensino Superior Credenciadas por Curso. Brasília, 2014. http://emec.gov.br Acesso em: 20 mar. 2017.

Brasileiro, T. S. A. \& Souza, M. P. R. (2010). Psicologia, Diretrizes Curriculares e Processos Educativos na Amazônia: um estudo da formação de psicólogos. Revista Semestral da Associação Brasileira de Psicologia Escolar e Educacional. Campinas, 14(1), 105-120.

Catani, A. M; Oliveira, J. F. \& Dourado, L. F. (2001). Política educacional, mudanças no mundo do trabalho e reforma curricular nos cursos de graduação no Brasil. Educação \& Sociedade, Campinas, 22(75), 67-83.

Cirino, S. D.; Dnupp, D. F. D.; Lemos, S. L.; \& Domingues, S. (2007). As novas diretrizes curriculares: uma reflexão sobre a licenciatura em Psicologia. Temas psicol., Ribeirão Preto, 15(1).

Czeresnia, D. \& Freitas, C.M. (Org.). (2003). Promoção da Saúde conceitos, reflexões e tendências. Rio de Janeiro: Editora Fiocruz

Ferreira Neto, J. L. (2010). A atuação do psicólogo no SUS: Análises de Alguns Impasses. Psicologia Ciência e Profissão, 2010, 30 (2), 390-403.

Haydt, R. C. C. (2006). Curso de didática geral. (8a ed.) São Paulo: Ática.

Hüning, S. M. , Silva, A. K., Silva, W. V. N. \& Lessa, F. M. S.(2013). Formação para o SUS nos cursos de psicologia em Alagoas. Psicologia em Estudo, 18(1), 157-167. https://dx.doi.org/10.1590/S1413-73722013000100016
Noronha, J. C; Lima, L. \& Machado, C. V. (2008). O Sistema Único de Saúde - SUS. Giovanella, L., Escorel, S., Lobato, L. V. C., Noronha, J. C. \& Carvalho, A. I. (Org.). Politicas e sistema de saúde no Brasil. Rio de Janeiro: Fiocruz/Cebes, 435-472.

Ribeiro, S. L.; Luzio, C. A. (2008). As diretrizes curriculares e a formação do psicólogo para a saúde mental. Psicologia em Revista, 14(2), 203-220.

Rodrigues, R. M. \& Caldeira, S. (2009). Formação na Graduação em Enfermagem no Estado do Paraná. Rev. bras. enferm. 62(3), 417-423.

Rodrigues, R. M. (2005). Diretrizes curriculares para a graduação em enfermagem no Brasil: contexto, conteúdo e possibilidades para a formação. Tese de Doutorado, Universidade de Campinas, Campinas-SP.

Saviani, D. (1998). Da Nova LDB ao Novo Plano Nacional de Educação: por uma outra Política Educacional. Campinas-SP. Autores Associados

Veiga, I. P. A. (2007). Projeto político-pedagógico da escola. Citado por Veiga, I. P. A. (Org.) Projeto político-pedagógico: uma construção possível, 11-35. Campinas-SP.

Submetido em: 30-5-2017

Aceito em: 28-6-2018 